The Journal of Animal \& Plant Sciences, 31(2): 2021, Page: 386-393

ISSN (print): 1018-7081; ISSN (online): 2309-8694

\title{
ESTIMATING RELATIONSHIP BETWEEN LIVE BODY WEIGHT AND TYPE TRAITS AT WEANING AND SIX MONTHS OF AGE IN BAFRA LAMBS USING CANONICAL CORRELATION ANALYSIS
}

\author{
D. Ozen ${ }^{1 *}$, A. Kocakaya ${ }^{2}$ and C. Ozbeyaz ${ }^{2}$ \\ ${ }^{1}$ Department of Biostatistics, ${ }^{2}$ Department of Animal Science Division of Animal Husbandry and Animal Nutrition, \\ Faculty of Veterinary Medicine, Ankara University, 06110, Diskapi, Ankara, Turkey \\ * Corresponding Author's e-mail: ozen@ankara.edu.tr
}

\begin{abstract}
Aim of this study was to use canonical correlation analysis technique to reveal the relationship between seven morphological traits (live weight, withers height, chest depth, body length, chest width, rump width and chest circumference) measured at weaning time (X-Set) and six months age (Y-Set) in a multidimensional form from a total of 71 male Bafra lambs raised at Gözlü Agricultural Enterprise located in Konya Province, Turkey. Seven pairs of canonical dimensions were generated of which only the first one $\left(\mathrm{U}_{1} \mathrm{~V}_{1}\right)$ was found statistically significant $\left(\mathrm{r}_{\mathrm{c}}=0.674\right.$, $\mathrm{p}<0.05$ ). Canonical correlation analysis revealed that all correlations were uniformly large which shows both of the canonical variates $\left(\mathrm{U}_{1}\right.$ and $\left.\mathrm{V}_{1}\right)$ can be considered as an overall measure of $\mathrm{X}$ and $\mathrm{Y}$ variable sets. Raw canonical coefficients showed that a one unit increase in live weight and wither's height at weaning leads to 0.118 and 0.127 units increase in linear combination of measurements at six months of age, respectively. Also, the most influential traits were wither's height, chest circumference and chest girth in the relationship of covariates measured at weaning time and six months age which can form the basis for early selection criteria in Bafra lambs.
\end{abstract}

Keywords: Bafra lamb, Canonical correlation analysis, Morphological traits, Weaning traits.

https://doi.org/10.36899/JAPS.2021.2.0226

Published online October 03,2020

\section{INTRODUCTION}

Sheep breeding has a significant role to play in developing world in providing both food and non-food products. With an estimated of 33.67 million of a population, sheep breeding has an important place in Turkey's livestock industry. Turkey is also considered to be among the first ten World countries in terms of its sheep population (Faostat, 2018). The majority of the sheep population in Turkey is composed of multi-purpose indigenous breeds, producing milk, meat and wool. Yield level of these sheep varies according to breeds, but is generally low. Bafra breed is a registered crossbred genotype of sheep ( $3 / 4$ Chios $+1 / 4$ Karayaka) which is relatively disease resistant, prolific, highly yielding and environmentally adopted in many regions of Turkey (Atasoy et al., 2003; Akçapinar et al., 2005). Many studies reported milk yield and milking traits (Unal et al. 2008), meat production traits (Yakan and Unal, 2010), fertility traits and growth characteristics (Unal et al., 2003), fleece traits (Unal et al., 2004) and adaptation capability (Akcapinar et al., 2002; Gungor and Akcapinar, 2013) of this breed. However, the knowledge of the relationship between body measurements and live weight is limited.

In animal husbandry, body measurements are important in terms of giving information about the morphological structure and development ability of animals. Knowing the level and course of the relationship between live weight and body measurements, is of great importance in terms of defining animal performance, selection practices and management applications. Researchers generally use simple correlation analysis in order to determine the strength and direction of linear associations among various body measurements (Cankaya and Kayaalp, 2007; Iqbal et al., 2013; Iqbal et al., 2014; Cilek and Petkova, 2016; Sandeep et al., 2018). However, simple correlation analysis is dependent on the coordinate system in which the variables are described, meaning that even if there is a very strong linear relationship between two multidimensional measurements, this relationship may not be visible in a simple correlation analysis (Zheng and Xue, 2009). Canonical correlation analysis (CCA) was developed by Hotelling (Hotelling, 1936) and can find the coordinate system that is most favourable for correlation analysis. It is widely used in determination of the relationship between multiple measurements taken from the same animal in different time points providing information that can form the basis of indirect selection, in animal science. Also, it would be used in timing and rearranging of management applications in lamb meat production. Applications of CCA to determine the relationship between multiple measurements such as pre-post slaughter traits of Ross 308 broiler chickens (Mendes and Akkartal, 2007) and Karayaka hoggets (Cankaya et al., 
2009), body weights and carcass yields of Karayaka sheep (Cam et al., 2010), body measurement and live weight of Ile de France x Akkaraman (G1) (Tatar and Elicin, 2002), milk and wool yields in Awassi sheep (Keskin and Dag, 2009), testicular and body measurements of Awassi ram lambs (Emsen and Davis, 2004) and some traits measured at different time points in Merino lambs (Sahin et al., 2011) were reported in previous studies. However, to the best of our knowledge, there is no application of canonical correlation analysis for investigation the relationships of some body measurements and live weights measured in different time periods in Bafra breed.

The aim of this study was to estimate interrelationship between morphological characters and live weight measured at weaning time and six-months age in Bafra lambs using canonical correlation analysis.

\section{MATERIALS AND METHODS}

Animal Material: The study was conducted at stateowned Gözlü Agricultural Enterprise located in Konya

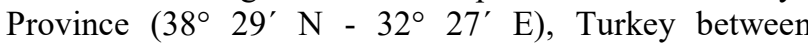
February and August 2018. Konya is in central Anatolia, where semi-arid (steppe) climate condition prevails. During the experiment, minimum and maximum temperature ranged from 3.1 to $28^{\circ} \mathrm{C}$. Relative humidity varied from $42.50 \%$ to $62.8 \%$. A total of 71 male Bafra lambs with a mean initial weight of $3.62 \pm 0.56 \mathrm{~kg}$ were used in the study. Lambs were kept in a semi-open shed until the sale at six months of age and fed with the routine programme of the enterprise. Live weight and the following body measurements of the animals were taken at weaning period (three-month of age) and six-months of age (Table 1). All data were collected by one person to ensure standardization.

Table 1. Measured variables and variable coding used in the study.

\begin{tabular}{lcc} 
Variable name & $\begin{array}{c}\text { For Weaning Period } \\
\text { (X-Variable Set) }\end{array}$ & $\begin{array}{c}\text { For Six month age } \\
\text { (Y-Variable Set) }\end{array}$ \\
\hline Live Weight $(\mathrm{kg})$ & LW_W & LW_SM \\
Withers Height $(\mathrm{cm})$ & WH_W & WH_SM \\
Chest Depth $(\mathrm{cm})$ & CD_W & CD_SM \\
Body Length $(\mathrm{cm})$ & BL_W & BL_SM \\
Chest Width $(\mathrm{cm})$ & CW_W & CW_SM \\
Rump Width $(\mathrm{cm})$ & RW_W & RW_SM \\
Chest Circumference $(\mathrm{cm})$ & CC_W & CC_SM \\
\hline
\end{tabular}

Live weight was recorded by using digital scale and the scale was accurate to 5 gr. Definitions regarding the morphological traits measured were given as follows:

Withers Height $(\mathrm{cm})$ : Distance from the withers to the ground.

Chest Depth (cm): Distance from the withers to the sternum.

Body Length $(\mathrm{cm})$ : Distance from base of tail to the base of the neck.

Chest Width $(\mathrm{cm})$ : The distances between the tips of the scapula.

Rump Width $(\mathrm{cm})$ : The width between tuber

coxae

Chest Circumference $(\mathrm{cm})$ : Around the chest just behind the front legs and withers.

Statistical Analysis: Canonical correlation analysis was used to investigate the association among the morphological traits at weaining period (X set of variables) and 6 months of age ( $\mathrm{Y}$ set of variables). Pearson correlation analysis was also used to determine the linear relationship between traits.

Canonical Correlation Analysis (CCA): The correlation matrix of all variables was divided into four parts: $R_{x x}$ (the correlations among the $\mathrm{X}$ variables), $\mathrm{R}_{\mathrm{yy}}$ (the correlations among the $\mathrm{Y}$ variables), $\mathrm{R}_{\mathrm{xy}}$ (the correlations between the $\mathrm{X}$ and $\mathrm{Y}$ variables), $\mathrm{R}_{\mathrm{yx}}$ (the correlations between $\mathrm{Y}$ and $\mathrm{X}$ variables) which is shown below.

$\left[\begin{array}{ll}R_{x x} & R_{x y} \\ R_{y x} & R_{y y}\end{array}\right]$

Then, the equation used for canonical correlation analysis can be defined using the singular value decomposition of a matrix $\mathrm{R}$ where,

$$
R=R_{y y}^{-1} R_{y x} R_{x x}^{-1} R_{x y}
$$

Eigenvalues were obtained by analyzing the $\mathrm{R}$ matrix. Eigenvectors were obtained for the $\mathrm{Y}$ set of variables first and then calculated for the $\mathrm{X}$ set of variables using the following,

$$
\begin{aligned}
& B_{y}=\left(R_{y y}^{-1 / 2}\right)^{\prime} \hat{B}_{y} \\
& B_{x}=R_{x x}^{-1} R_{x y} B_{y}
\end{aligned}
$$

The eigenvector that corresponds to each eigenvalue was transformed into the canonical coefficients used to combine the original variables into the composite variate (Tabachnick and Fidell, 2007). 
The hypothesis for the statistical significance of the canonical coefficients was established as;

$$
H_{\mathrm{o}}: r_{c 1}=r_{c 1}=\ldots=r_{c r}=0
$$

$H_{1}: r_{c i} \neq 0$ at least one $i=1,2, \ldots k$ Hypothesis testing for canonical correlation was tested using Wilk's Lambda:

$$
\Lambda_{m}=\prod_{i=1}^{m}\left(1-\lambda_{i}\right)
$$

where eigenvalue, $\lambda_{i}$, is equal to the squared canonical correlation, $r_{c i}^{2}$ for the pair of canonical variates, generated across $m$ canonical correlations. The significance of canonical correlations was evaluated as a chi-square variable, where $\mathrm{n}$ is the number of cases, $\mathrm{kx}$ is the number of variables in $\mathrm{X}$ variable set, $\mathrm{ky}$ is the number in the $\mathrm{Y}$ variable set,

$$
\chi^{2}=-\left[N-1-\left(\frac{k_{x}+k_{y}+1}{2}\right)\right] \ln \Lambda_{m}
$$

Scores on canonical variates ( $U$ and $V$ ) were estimated using the standardized scores on the original variates, $Z_{x}$ and $Z_{y}$ and the canonical coefficients of $B_{x}$ and $\mathrm{B}_{\mathrm{y}}$ with the following equation:

$$
\begin{aligned}
& U=Z_{x} B_{x} \\
& V=Z_{y} B_{y}
\end{aligned}
$$

Loading matrices $\left(A_{x}\right.$ and $\left.A_{y}\right)$, which are matrices of correlations between the variables and canonical coefficients were calculated as,

$$
A_{x}=R_{x x} B_{x}, \quad A_{y}=R_{y y} B_{y}
$$

The proportion of variance $(p v)$ extrated from a set of variables by a canonical variate of the set was calculated by the following equations,

$$
p v_{x c}=\sum_{i=1}^{k_{x}} \frac{a_{i x c}^{2}}{k_{x}}
$$

Table 2. Descriptive statistics. $p v_{y c}=\sum_{i=1}^{k_{y}} \frac{a_{i y c}^{2}}{k_{y}}$

Where $a^{2}$ represents squared correlations and $k$ represents number of variables in the set.

Redundancy (rd) was calculated with the following equation:

$$
r d=(p v)\left(r_{c}^{2}\right)
$$

All the computational work was performed using STATA 12.1 MP4 statistical software (StataCorp, 2011).

\section{RESULTS AND DISCUSSION}

Descriptive statistics for each characters and their relationship among the morphological traits 71 Bafra lambs were given in Table 2 and Table 3. According to the bivariate correlation matrix, the strongest correlations were between weight and chest girth $(\mathrm{r}=0.61)$, followed by weight and withers height $(\mathrm{r}=0.53)$ for weaning period; weight and withers height $(r=0.67)$ followed by weight and chest depth $(r=0.64)$ for the 6th month of age; withers height (weaning period) and withers height (six month of age) $(r=0.54)$ for the interrelationships between two measurement periods (Table 3). The correlation of live weight between two measurement time periods was relatively weaker than that of the relationship between weight and body measurements. Those findings are in line with several studies conducted with Karayaka sheep (Cam et al., 2010; Tahtali et al., 2012), Bafra sheep (Kilic and Ozbeyaz, 2010), Malya sheep (Cilek and Petkova, 2016), Harnali sheep (Sandeep et al., 2018), Kajli lambs (Iqbal et al., 2014) and Beetal goats (Iqbal et al., 2013).

\begin{tabular}{ccccccc}
\hline Variable & Mean & Std. Error & Std. Deviation & Median & Minimum & Maximum \\
\hline LW_W & 22.79 & 0.46 & 4 & 22.7 & 13.9 & 33.4 \\
WH_W & 57.08 & 0.42 & 3.64 & 56.15 & 45 & 66 \\
CD_W & 22.52 & 0.2 & 1.77 & 22 & 19.2 & 29 \\
BL_W & 49.05 & 0.36 & 3.12 & 49 & 40 & 57 \\
CW_W & 14.13 & 0.14 & 1.23 & 14 & 10 & 16 \\
RW_W & 13.73 & 0.16 & 1.42 & 14 & 11 & 17.03 \\
CC_W & 68.81 & 0.46 & 3.97 & 68 & 60 & 78 \\
W_SM & 31.95 & 0.62 & 5.41 & 33.11 & 22.5 & 43.1 \\
WH_SM & 61.71 & 0.35 & 3.05 & 61.89 & 53 & 66 \\
CD_SM & 25.59 & 0.23 & 2.02 & 25.9 & 21 & 29 \\
BL_SM & 54.26 & 0.23 & 2.04 & 54 & 50 & 59 \\
CW_SM & 16.72 & 0.16 & 1.35 & 17 & 14 & 19 \\
RW_SM & 17.72 & 0.21 & 1.81 & 18 & 14 & 23 \\
CC_SM & 80.6 & 0.73 & 6.36 & 80.55 & 69 & 93 \\
\hline
\end{tabular}

LW: Live weight, WH: Withers Height, CD: Chest Depth, BL: Body Length, CW: Chest Width, RW: Rump Width, CC: Chest Circumference; _W: Weaning Period,_SM: Six months of age 
Many morphological traits are frequently measured and recorded in studies on sheep breeding as these measurements are important indicators of the live weights in animal growth. However, difficulties arise in explaining the relationship between these characters in a comprehensive way in practice (Fourie et al., 2002). To better explain the relationship between two sets of variables by finding linear combinations of variables that maximally correlate, seven pair of canonical variates in which each of them is orthogonal to the other canonical variates except for the one with which its correlation has been maximized, were generated. For this particular model, there were seven canonical dimensions of which only the first one $\left(U_{1} V_{1}\right)$ was statistically significant $(\mathrm{P}=0.001)$ (Table 4). The possible number of such pairs is dependent to the number of morphological traits measured in the smallest group. In previous studies, number of generated canonical pairs varied from three (Cankaya and Kayaalp, 2007) to six (Tatar and Elicin, 2002; Cankaya et al., 2009; Sahin et al., 2011), of which only the first pair was statistically significant except the study of (Sahin et al., 2011)'s.

Raw canonical coefficients to define the linear relationship between traits at weaning and the traits at six months age were given in Table 5. Results showed that a one unit increase in live weight and wither's height at weaning leads to 0.118 and 0.127 units increase in linear combination of measurements at six months of age, respectively. However, since the variables in the model had different standard deviations, the standardized coefficients were also given to allow for easier comparisons among the variables.

The standardized canonical coefficients for canonical variates were given in Table 6 . It was revealed that the biggest contributor on the $U_{1}$ canonical variate was live weight followed by withers height and rump width for $\mathrm{X}$ variable set, while the biggest contributor on the $\mathrm{V}_{1}$ canonical variate was live weight, followed by withers height and chest depth. Considering the variable live weight; one standard deviation increase in live weight in weaning period leads to a 0.47 standard deviation increase in the score on the first canonical variate $\left(\mathrm{U}_{1}\right)$ for $\mathrm{X}$ variable set, while one standard deviation increase in live weight at six months leads to a 0.97 standard deviation increase in the score on the first canonical variate $(\mathrm{V} 1)$ for $\mathrm{Y}$ variable set when the other variables in the model are held constant (Table 6). In a study conducted with Karayaka lambs (Tahtali et al., 2012), largest contributor to the variable set consisting of morphological traits at weaning time was withers height followed by chest girth.

The loadings of the variables in each set on the canonical dimensions which represents the correlations between variables and the opposite canonical variates were given in Table 7. Results showed that all correlations are uniformly large which shows both of the canonical variates $\left(\mathrm{U}_{1}\right.$ and $\left.\mathrm{V}_{1}\right)$ can be considered as an overall measure of $\mathrm{X}$ and $\mathrm{Y}$ variable sets, respectively. The cross loadings suggested that live weight at weaning period, withers height and chest depth were more influential than other four traits in forming V1, while weight at six months age, wither's height and chest circumference were more influential in forming $\mathrm{U} 1$ in weaning period (Table 7). Previous studies reported high influence of withers height (Tahtali et al., 2012) and chest girth (Cankaya and Kayaalp, 2007; Tahtali et al., 2012) for weaning period. Also, Atta (2004) reported high influence of heart girth on live weight.

In the present study, $48.7 \%$ of the total variation was explained by canonical variate $\mathrm{U}_{1}$, while the $22.1 \%$ of the variation was explained by canonical variable $\mathrm{V}_{1}$ for traits measured in weaning period. In contrast, $43.3 \%$ of the total variation in morphological traits at six months of age was explained by canonical variate $\mathrm{V}_{1}$, and $25 \%$ of the ratio was explained by canonical variate $U_{1}$. Although the amount of shared variance that can be explained by each canonical function was relatively low, no generally accepted guidelines have been established for the minimum acceptable redundancy index (Joseph et al., 2004). However, results of this study are compatible and in line with previous studies (Cankaya et al., 2008; Sahin et al., 2011), supporting the theoretical and practical significance of the research problem being investigated. 
Table 3. Bivariate correlations between morphological traits.

\begin{tabular}{|c|c|c|c|c|c|c|c|c|c|c|c|c|c|c|}
\hline & $\mathbf{W}_{-} \mathbf{W}$ & W_SM & WH_W & CD_W & $\mathbf{C W} \mathbf{W}$ & BL_W & RW_W & $\mathrm{CC}_{-} \mathrm{W}$ & WH_SM & CD_SM & BL_SM & CW_SM & RW_SM & CC_SM \\
\hline W_W & 1 & & & & & & & & & & & & & \\
\hline W_SM & $0.39^{* * *}$ & 1 & & & & & & & & & & & & \\
\hline W̄H_W & $0.53^{* * *}$ & $0.43^{* * *}$ & 1 & & & & & & & & & & & \\
\hline CD_W & $0.45^{* * *}$ & $0.47^{* * *}$ & $0.46^{* * *}$ & 1 & & & & & & & & & & \\
\hline CW_W & $0.36^{* * *}$ & $0.35^{* *}$ & $0.32^{* *}$ & $0.36^{* *}$ & 1 & & & & & & & & & \\
\hline $\mathrm{BL}-\mathrm{W}$ & $0.37^{* * *}$ & $0.25^{*}$ & 0.21 & $0.24^{*}$ & 0.24 & 1 & & & & & & & & \\
\hline RW_W & $0.25^{*}$ & $0.34^{* *}$ & 0.19 & 0.29 & $0.32^{* *}$ & 0.15 & 1 & & & & & & & \\
\hline $\mathrm{CC}_{-}-\mathrm{W}$ & $0.61^{* * *}$ & $0.33^{* *}$ & $0.38^{* *}$ & $0.36^{* *}$ & $0.30^{* *}$ & $0.35^{* *}$ & 0.20 & 1 & & & & & & \\
\hline WH_SM & $0.42^{* * *}$ & $0.67^{* * *}$ & $0.54^{* * *}$ & $0.34^{* *}$ & $0.29^{*}$ & $0.33^{* *}$ & $0.28^{*}$ & $0.29^{*}$ & 1 & & & & & \\
\hline CD_SM & $0.38^{* *}$ & $0.63^{* * *}$ & $0.34^{* *}$ & $0.41^{* * *}$ & $0.27^{*}$ & 0.22 & 0.21 & $0.37^{* *}$ & $0.64^{* * *}$ & 1 & & & & \\
\hline BL_SM & $0.38^{* *}$ & $0.49^{* * *}$ & $0.27^{*}$ & $0.33^{* *}$ & 0.10 & $0.38^{* *}$ & $0.23^{*}$ & 0.21 & $0.54^{* * *}$ & $0.48^{* * *}$ & 1 & & & \\
\hline CW_SM & $0.40^{* * *}$ & $0.61^{* * *}$ & 0.18 & $0.31^{* *}$ & $0.31^{* *}$ & 0.15 & 0.16 & 0.19 & $0.52^{* * *}$ & $0.64^{* * *}$ & $0.37^{* *}$ & 1 & & \\
\hline RW_SM & $0.34^{* *}$ & $0.51^{* * *}$ & $0.25^{*}$ & $0.36^{* *}$ & $0.31^{* *}$ & 0.13 & $0.38^{* *}$ & 0.10 & $0.42^{* * *}$ & $0.44^{* * *}$ & $0.51^{* * *}$ & $0.46^{* * *}$ & 1 & \\
\hline $\mathrm{CC}_{-} \mathrm{SM}$ & $0.48^{* * *}$ & $0.62^{* * *}$ & $0.29^{*}$ & $0.38^{* *}$ & $0.25^{*}$ & $0.29^{*}$ & $0.34^{* *}$ & $0.36^{* *}$ & $0.67^{* * *}$ & $0.68^{* * *}$ & $0.66^{* * *}$ & $0.51^{* * *}$ & $0.49^{* * *}$ & 1 \\
\hline
\end{tabular}

LW: Live weight, WH: Withers Height, CD: Chest Depth, BL: Body Length, CW: Chest Width, RW: Rump Width, CC: Chest Circumference; _W: Weaning Period, _SM: Six months of age 
Table 4. Primary results for the canonical correlation analysis.

\begin{tabular}{cccccccc}
\hline $\begin{array}{c}\text { Pair of } \\
\text { Canonical } \\
\text { Variables }\end{array}$ & $\begin{array}{c}\text { Canonical } \\
\text { Correlation }\end{array}$ & $\begin{array}{c}\text { Squared } \\
\text { Canonical } \\
\text { Correlation }\end{array}$ & F-Value & Df $_{1}$ & Df $_{2}$ & $\begin{array}{c}\text { Probability } \\
\text { Pr>F F }\end{array}$ & $\begin{array}{c}\text { Wilks' } \\
\text { Lambda }\end{array}$ \\
\hline & 0.674 & 0.455 & 1.78 & 49 & 319 & 0.001 & 0.293 \\
$\mathrm{U}_{1} \mathrm{~V}_{1}$ & 0.482 & 0.232 & 1.17 & 36 & 279 & 0.236 & 0.538 \\
$\mathrm{U}_{2} \mathrm{~V}_{2}$ & 0.378 & 0.143 & 0.96 & 25 & 239 & 0.525 & 0.702 \\
$\mathrm{U}_{3} \mathrm{~V}_{3}$ & 0.327 & 0.107 & 0.84 & 16 & 199 & 0.636 & 0.818 \\
$\mathrm{U}_{4} \mathrm{~V}_{4}$ & 0.228 & 0.052 & 0.65 & 9 & 161 & 0.751 & 0.916 \\
$\mathrm{U}_{5} \mathrm{~V}_{5}$ & 0.178 & 0.032 & 0.57 & 4 & 134 & 0.686 & 0.967 \\
$\mathrm{U}_{6} \mathrm{~V}_{6}$ & 0.039 & 0.001 & 0.1 & 1 & 68 & 0.751 & 0.999 \\
$\mathrm{U}_{7} \mathrm{~V}_{7}$ & & & & & \\
\hline
\end{tabular}

Table 5. Linear combinations for canonical correlations (raw coefficients) of $U 1$ to predict canonical variate of traits at six months of age (V1).

\begin{tabular}{ccccccc}
\hline & \multirow{2}{*}{ Coefficient } & Std. Err. & T & \multirow{2}{*}{ P } & \multicolumn{2}{c}{ 95\% Confidence Interval } \\
\cline { 6 - 7 } & & 0.045 & 2.57 & 0.012 & Lower Bound & Upper Bound \\
\hline W_W & 0.118 & 0.043 & 2.93 & 0.004 & 0.026 & 0.209 \\
WH_W & 0.127 & 0.092 & 0.97 & 0.336 & -0.094 & 0.213 \\
CD_W & 0.089 & 0.129 & 1.09 & 0.278 & -0.116 & 0.273 \\
CW_W & 0.141 & 0.048 & 0.61 & 0.546 & -0.067 & 0.398 \\
BL_W & 0.029 & 0.101 & 2.76 & 0.007 & 0.078 & 0.482 \\
RW_W & 0.280 & 0.044 & 1.78 & 0.079 & 0.009 & 0.166 \\
CC_W & 0.08 & &
\end{tabular}

LW: Live weight, WH: Withers Height, CD: Chest Depth, BL: Body Length, CW: Chest Width, RW: Rump Width, CC:

Chest Circumference; _W: Weaning Period

Table 6. Standardized canonical coefficients for canonical variables.

\begin{tabular}{cccccccc}
\hline & \multicolumn{7}{c}{ X Variable Set } \\
\hline \multirow{2}{*}{$\mathrm{U}_{1}$} & W_W & WH_W & CD_W & CW_W & BL_W & RW_W & CC_W \\
& 0.471 & 0.463 & 0.158 & 0.174 & 0.092 & 0.397 & 0.312 \\
& & & & Y Variable Set & & & \\
$\mathrm{V}_{1}$ & W_SM & WH_SM & CD_SM & CW_SM & BL_SM & RW_SM & CC_SM \\
& 0.967 & 0.451 & -0.359 & -0.097 & -0.218 & 0.279 & 0.121
\end{tabular}

LW: Live weight, WH: Withers Height, CD: Chest Depth, BL: Body Length, CW: Chest Width, RW: Rump Width, CC: Chest Circumference;_W: Weaning Period,_SSM: Six months of age

Table 7. Cross-loadings of the original variables with opposite canonical variables.

\begin{tabular}{|c|c|c|c|c|c|c|c|}
\hline & & & & X Variable Set & & & \\
\hline \multirow[b]{2}{*}{$\mathrm{V}_{1}$} & W W & WH W & CD W & $\mathrm{CW} \mathbf{W}$ & BL W & RW W & CC W \\
\hline & $0 . \overline{4} 73$ & $0.4 \overline{6} 1$ & $0 . \overline{4} 24$ & $0.3 \overline{9} 0$ & $0 . \overline{23} 7$ & $0.3 \overline{99}$ & $0 . \overline{2} \overline{4}$ \\
\hline $\mathrm{U}_{1}$ & $\underset{0.625}{\text { W_SM }}$ & $\begin{array}{c}\text { WH_SM } \\
0.552\end{array}$ & $\begin{array}{c}\text { CD_SM } \\
0.436\end{array}$ & $\begin{array}{c}\text { Y Variable Set } \\
\text { CW_SM } \\
0.394\end{array}$ & $\begin{array}{c}\text { BL_SM } \\
0.438\end{array}$ & $\underset{0.515}{\mathbf{R W} \mathbf{S M}}$ & $\begin{array}{c}\text { CC_SM } \\
0.508\end{array}$ \\
\hline
\end{tabular}

LW: Live weight, WH: Withers Height, CD: Chest Depth, BL: Body Length, CW: Chest Width, RW: Rump Width, CC:

Chest Circumference;_W: Weaning Period,_SM: Six months of age

Conclusion: Body measurements are important in terms of providing information about the morphological structure of animals. This study has reported the association between some morphological traits measured 
at weaning time and six months age in Bafra breed first time. The study revealed that the most influential factors were withers height, chest circumference and chest girth in relationship of traits measured at weaning time and six months age.

One of the advantages of the method used in this study was to evaluate the effect of morphological measurements as a combination of variables, rather than using only a single variable to predict on the other side of the equation which does not report the information concerning dimensionality.

Farm management is a problem-solving and decision-making activity and knowing the relationship between live body weight and type traits at weaning and six months of age may provide the farmer forming an early basis for his management activity such as in reorganizing the breeding groups or production.

In conclusion, the canonical correlation technique could be a comprehensive tool to investigate associations among useful traits providing information that can form the basis of indirect selection and management applications.

\section{REFERENCES}

Akcapinar, H., N. Unal and F. Atasoy (2005). The effects of early age mating on some production traits of Bafra (chios X karayaka B1) sheep. Turk. J. Vet. Anim. Sci. 29 (2): 531-536.

Akcapinar, H., N. Unal, F. Atasoy, C. Özbeyaz and M. Aytaç (2002). Karayaka ve bafra (sakız X karayaka G1) koyunlarinin lalahan hayvancilik arastirma enstitusu sartlarina uyum kabiliyeti. Lalahan. Hay. Araşt. Enst. Derg. 42 (1): 11-24.

Atasoy, F., N. Unal, H. Akcapinar and D. Mundan (2003). Some production traits of karayaka and bafra (chios x karayaka b1) sheeps. Turk. J. Vet. Anim. Sci. 27 (1): 259-264.

Atta, M. (2004). Use of heart girth, wither height and scapuloischial length for prediction of liveweight of Nilotic sheep. Small. Ruminant. Res. 55 (1-3): 233-237.

Cam, M., M. Olfaz and E. Soydan (2010). Body measurements reflect body weights and carcass yields in Karayaka sheep. Asian. J. Anim. Vet. Adv. 5 (2): 120-127.

Cankaya, S., A. Altop, M. Olfaz and G. Erener (2009). Canonical correlation analysis for estimation of relationships between some traits measured at pre- and post-slaughtering periods in Karayaka hoggets. Anadolu. Tarım. Bilim. Derg. 24 (1): 61-66.

Cankaya, S. and G.T. Kayaalp (2007). Estimation of relationship between live weights and some body measurements in german farm $x$ hair crossbred by canonical correlation analysis. J. Anim Prod. 48 (2): 27-32.

Cankaya, S., E. Yazgan, G. Kayaalp, Z. Gocmez and U. Serbester (2008). Canonical correlation analysis for estimation of relationship between some body measurements at the birth and 6 month periods in Holstein Friesian calves. J. Anim. Vet. Adv. 7(8): 953-958.

Cilek, S., and M. Petkova (2016). Phenotypic correlations between some body measurements and prediction of body weight of Malya sheep. Bulg. J. Agric. Sci. 22(1):99-105.

Emsen, E., and M.E. Davis (2004). Canonical correlation analyses of testicular and body measurements of awassi ram lambs. J. Anim. Vet. Adv. 3 (12): 842-845.

Faostat (2018). Food and agriculture organization of united nations. FAOSTAT statistical database, Rome.

Fourie, P., F. Neser, J. Olivier and C. Van Der Westhuizen (2002). Relationship between production performance, visual appraisal and body measurements of young Dorper rams. S. Afr. J. Anim. Sci. 32 (4): 256-262.

Gungor, İ., and H. Akcapinar (2013). Bafra genotipinin Ankara şartlarinda verim özellikleri. Lalahan. Hay. Araşt. Enst. Derg. 53 (2): 59-73.

Hotelling, H. (1936). Relations between two sets of variates. Biometrika 28 (3/4): 321-377.

Iqbal, M., K. Javed and N. Ahmad (2013). Prediction of body weight through body measurements in Beetal goats. Pakistan J. Sci. 65 (4): 458-461.

Iqbal, Z. M., K. Javed, M. Abdullah, N. Ahmad, A. Ali, A. Khalique, N. Aslam and U. Younas (2014). Estimation of body weight from different morphometric measurements in Kajli lambs. The J. Anim. Plant Sci. 24(3): 700-703

Joseph, F., J.R. Hair, R.E. Anderson, R.L. Tatham and W.C. Black (2004). Multivariate Data Analysis. 7th Ed. Pearson Education Limited; Essex. 151$181 \mathrm{p}$

Keskin, I. and B. Dag (2009). Investigation of relationship amongst milk and wool yield traits of Awassi sheep by using canonical correlation analysis. J. Anim. Vet. Adv. 8 (3): 464-468.

Kilic, I. and C. Özbeyaz (2010). Live weight estimation of karayaka and bafra (chios $\times$ karayaka B1) sheep using some body measurements. Lalahan. Hay. Araşt. Enst. Derg. 50 (1): 1-11.

Mendes, M. and E. Akkartal (2007). Canonical correlation analysis for studying the relationships between pre-and post slaughter traits of Ross 308 broiler chickens. Arch. Geflügelkonf. 71: 267-271.

Sahin, M., S. Cankaya and A. Ceyhan (2011). Canonical correlation analysis for estimation of 
relationships between some traits measured at weaning time and six-month age in Merino lambs. Bulg. J. Agric. Sci. 17 (5): 680-686.

Sandeep, K., S. P. Dahiya, Z. S. Malik and C. S. Patil (2018). Prediction of body weight from linear body measurements in sheep. Indian J. Anim. Res. 52(9): 1263-1266.

Tabachnick, B.G. and L.S. Fidell (2007). Using multivariate statistics. $5^{\text {th }}$ Ed. Allyn \& Bacon/Pearson Education; Washington. $576 \mathrm{p}$

Tahtali, Y., S. Cankaya, Z. Ulutas (2012). Canonical correlation analysis for estimation of relationships between some traits measured at birth and weaning time in Karayaka lambs. Kafkas. Uni. Vet. Fak. Derg. 18 (5): 839-844.

Tatar, A., and A. Elicin (2002). İle de France x Akkaraman (G1) melezi erkek kuzularında süt emme ve besi dönemindeki canlı ağırlık ve vücut ölçüleri arasındaki ilişkinin kanonik korelasyon metodu ile araştırılması. Ank. Üniv. Ziraat Fak. Tarım Bil. Der. 8 (1): 67-72.

Unal, N., F. Atasoy, H. Akcapinar and M. Erdogan (2003). Karayaka ve bafra (sakız x karayaka G1) koyunlarda döl verimi, kuzularda yaşama gücü ve büyüme. Turk. J. Vet. Anim. Sci. 27: 265272.

Unal, N., H. Akcapinar, F. Atasoy, S. Koçak and M. Aytaç (2004). Akkaraman, sakız x akkaraman ve kıvircık x akkaraman melezleri (F1, G1) ile karayaka ve bafra koyunlarda canlı ağırlık ve yapağı özellikleri. Lalahan. Hay. Araşt. Enst. Derg. 44 (2): 15-22.

Unal, N., H. Akcapinar, F. Atasoy, A. Yakan and M. Ugurlu (2008). Milk yield and milking traits measured with different methods in bafra sheep. Rev. Méd. Vét. 159 (10): 497-501.

Statacorp (2011). Stata Statistical Software: Release 12. College Station, TX: StataCorp LP.

Yakan, A., and N. Ünal (2010). Meat production traits of a new sheep breed called bafra in Turkey 2 . Meat quality characteristics of lambs. Trop. Anim. Health Pro. 42 (4): 743-750.

Zheng, N., and J. Xue (2009). Statistical learning and pattern analysis for image and video processing. Springer Science \& Business Media; London. 1$14 \mathrm{p}$. 